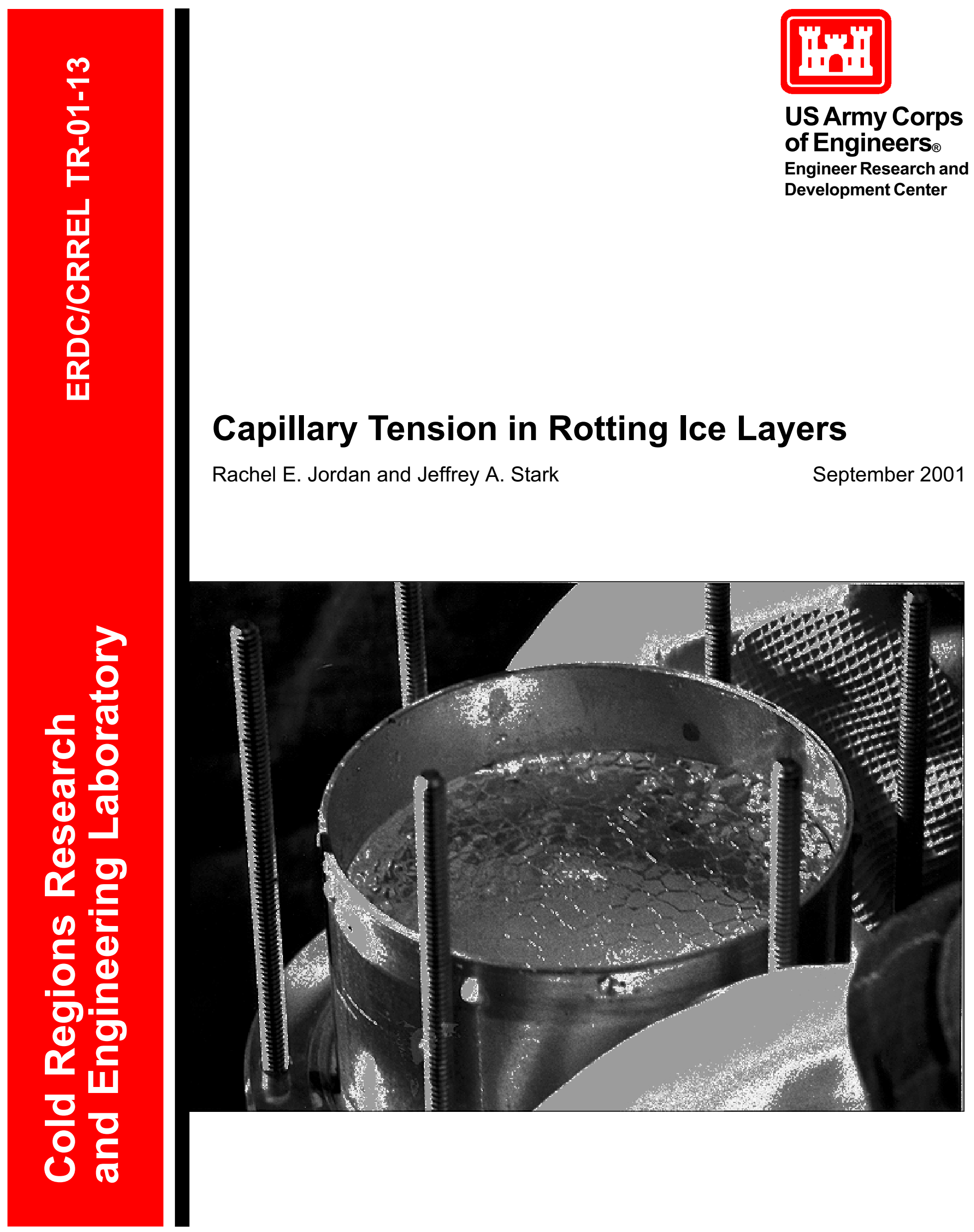


Abstract: This study examines the moisturetension constituent relationship of ice near $0^{\circ} \mathrm{C}$ by measuring its moisture characteristic curve. In this novel approach, we held ice samples in a Tempe cell submerged in a cold bath and removed water from the ice veins through incremental increases in air pressure. Observed air entry and water reentry pressures generally support an idealized flow path model of alternating vein segments and nodes. Re-entry of water into the air-filled ice samples occurred slowly over a period of weeks, suggesting low permeabilities on the order of $1 \times 10^{-18}$ $\mathrm{m}^{2}$. We conclude that ice desaturates and rewets in a manner similar to soils, with entry pressures on the order of silts.

Cover: Ice sample in a Tempe cell after being rotted for several months in a refrigerated bath held near $0^{\circ} \mathrm{C}$.

\section{How to get copies of CRREL technical publications:}

Department of Defense personnel and contractors may order reports through the Defense Technical Information Center:

DTIC-BR SUITE 0944
8725 JOHN J KINGMAN RD
$\begin{array}{ll}\text { FT BELVOIR VA 22060-6218 } \\ \text { Telephone } & (800) \text { 225-3842 } \\ \text { E-mail } & \text { help@dtic.mil } \\ & \text { msorders@dtic.mil } \\ \text { WwW } & \text { http://www.dtic.mil// }\end{array}$

All others may order reports through the National Technical Information Service:

NTIS

5285 PORT ROYAL RD

SPRINGFIELD VA 22161

Telephone (703) 487-4650

(703) 487-4639 (TDD for the hearing-impaired)

E-mail_orders@ntis.fedworld.gov

WWW http://www.ntis.gov/index.html

A complete list of all CRREL technical publications is available from

USACRREL (CEERD-IM-HL)

72 LYME RD

HANOVER NH 03755-1290

Telephone (603) 646-4338

E-mail_erhoff@crrel.usace.army.mil

For information on all aspects of the Cold Regions Research and Engineering Laboratory, visit our World Wide Web site:

http://www.crrel.usace.army.mil 


\section{Technical Report ERDC/CRREL TR-01-13}

\section{Capillary Tension in Rotting Ice Layers}

Rachel E. Jordan and Jeffrey A. Stark 


\section{PREFACE}

This report was prepared by Rachel E. Jordan, Research Physicist, Geophysical Sciences Branch, U.S. Army Engineer Research and Development Center (ERDC), Cold Regions Research and Engineering Laboratory (CRREL), Hanover, New Hampshire; and by Jeffrey A. Stark, Research Civil Engineer, Civil and Infrastructure Engineering Branch, CRREL.

The work was supported by Department of Defense Project 61102/AT24, Work Package 127, Snow Properties and Processes, Work Unit AT24-SP-001.

The authors acknowledge that this study would not have been possible without exceptional support from ERDC staff, especially Dr. Patrick Black for providing the refrigerated bath and for his encouragement in undertaking this experiment. The authors are particularly grateful to Nancy Perron for the impurities analysis and thin sections and to Christopher Williams, James Morse, and David Fisk for providing the temperature monitoring system, and thank Dr. Samuel Colbeck and Dr. Robert Davis for reviewing the manuscript.

This publication reflects the personal views of the authors and does not suggest or reflect the policy, practices, programs, or doctrine of the U.S. Army or Government of the United States. The contents of this report are not to be used for advertising or promotional purposes. Citation of brand names does not constitute an official endorsement or approval of the use of such commercial products. 


\section{CONTENTS}

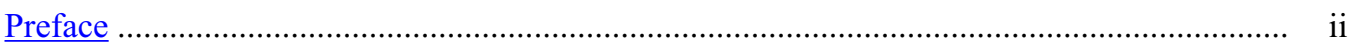

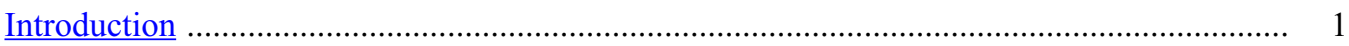

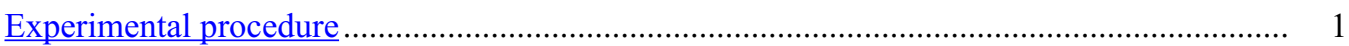

Sample preparation, installation, and analysis ................................................................. 2

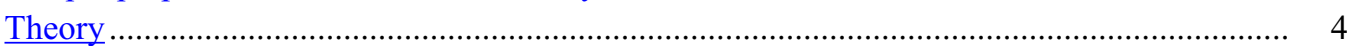

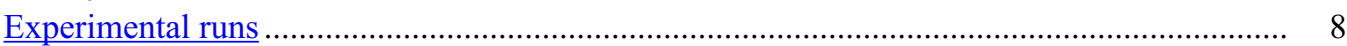

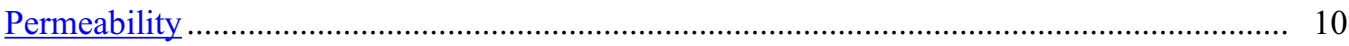

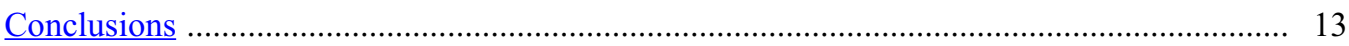

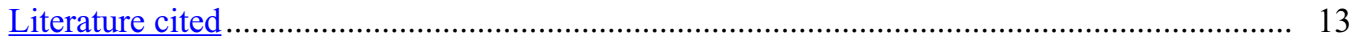

Appendix A: Solution of equation 12 for flow under tension ............................................ 15

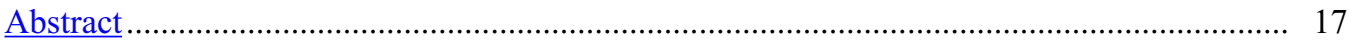

\section{ILLUSTRATIONS}

Figure

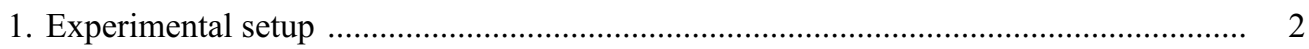

2. Ice sample is placed within a hermetically sealed Tempe cell ........................................ 2

3. Thin sections of ice samples under polarized light ......................................................... 3

4. Rotted ice samples from dismantled experiment .......................................................... 3

5. Geometry of water inclusions in ice ...................................................................... 5

6. Vein diameter vs. equilibrium temperature for a range of vein bulk molalities .............. 6

7. Volume fraction of liquid water vs. equilibrium temperature for a range of vein bulk

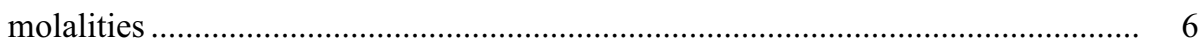

8. Geometry of liquid inclusions in contact with air ..................................................... 7

9. Volume of water exiting and re-entering Sample A vs. gauge pressure ........................... 9

10. Volume of water exiting and re-entering Sample B vs. gauge pressure …..................... 10

11. Days vs. volume of water re-entering Sample B ....................................................... 11

12. Idealized ice configuration used in flow computations ............................................ 11

\section{TABLES}

Table

1. Geometric definitions and relationships of ice structure .................................................. 4

2. Parameters used in computing flow rates through Sample B ..................................... 12 



\title{
Capillary Tension in Rotting Ice Layers
}

\author{
RACHEL E. JORDAN AND JEFFREY A. STARK
}

\section{INTRODUCTION}

Ice layers within snow or at the ground interface impede and divert the flow of water, thus leading to ponding and flooding during rain-on-snow events or during springtime thaws. Thawing of the basal ice layer affects terrain and road mobility. We must therefore question how ice behaves in contact with soil and in the context of layered porous media. An upgraded version of the SNTHERM snow model (Jordan 1991, Jordan et al. 1999) describes movement of water under thermal and liquid gradients in frozen and unfrozen soil. In this model (SLTHERM), temperature, pressure, ice, and liquid are coupled through constituent relationships that are universally used for soil (e.g., Black and Tice 1989, Black 1990). While water flow through glaciers is often treated as Darcian saturated flow (e.g., Colbeck 1976, Lliboutry 1996), here we consider whether constituent relationships similar to soil can be applied to ice. We ask the fundamental question whether air and liquid pathways can co-exist in ice, and if so, what configurations these phases take. In this paper we concentrate on the moisture-tension constituent relationship, which characterizes the air-liquid proportion in the pore space (or veins) as a function of pressure drop across the air/liquid interface (i.e., capillary tension). This work was in part prompted by Mader's (1992 $\mathrm{a}, \mathrm{b})$ theoretical and experimental study of equilibrium vein widths in temperature ice above $-0.5^{\circ} \mathrm{C}$.

\section{EXPERIMENTAL PROCEDURE}

We measured the moisture characteristic curve (MC) of ice with a procedure similar to that used for soils. Figure 1 shows a schematic of the experimental apparatus, in which an ice sample is placed within a her- metically sealed Tempe cell (Fig. 2) and then subjected to incremental increases in air pressure to "push" off the water. To control the ice vein width, and hence the permeability and entrance pressure, we submerged the ice sample in a refrigerated bath maintained just below $0^{\circ} \mathrm{C}$. The setup is kept within a coldroom maintained near $+5^{\circ} \mathrm{C}$. The Tempe cell consists of a brass cylinder and two plastic end pieces, sealed airtight with pairs of "O" rings. Water volume removed from the ice is measured through level changes in a graduated pipette connected by plastic tubing to the bottom of the Tempe cell. A 1-bar semipermeable ceramic plate (Soilmoisture Equipment Corp.) separates the pressurized air chamber from the open water reservoir. Bubbling pressure and hydraulic conductivity of the plate are specified as 20 to $30 \mathrm{PSI}$ and $3.46 \times 10^{-7} \mathrm{~cm} / \mathrm{sec}$. Water remained unfrozen within the ceramic stone because of its relatively high matric tension. A resistance-wire heater, connected to a temperature regulator, prevented freezeup of water within the submerged tubing.

We used a custom-made refrigerated bath for our experiments (Black 1986), consisting of a 20 -gallon container that is subjected to continual cooling by a refrigeration system. Because of its large thermal inertia, this bath is capable of constant temperature conditions $\left( \pm 0.003^{\circ} \mathrm{C}\right)$ for time durations on the order of weeks. A Bailey temperature controller is used to apply the necessary heat through an immersed heating element to bring the bath to the desired temperature. Although this approach is not energy efficient, it works well because it is easier to precisely warm the water than it is to cool it. To promote efficient energy exchange, the bath is continually mixed. We mounted the Tempe cell apparatus on a freestanding support to isolate it from the agitation of the bath.

We made experimental runs on two ice samples. The 


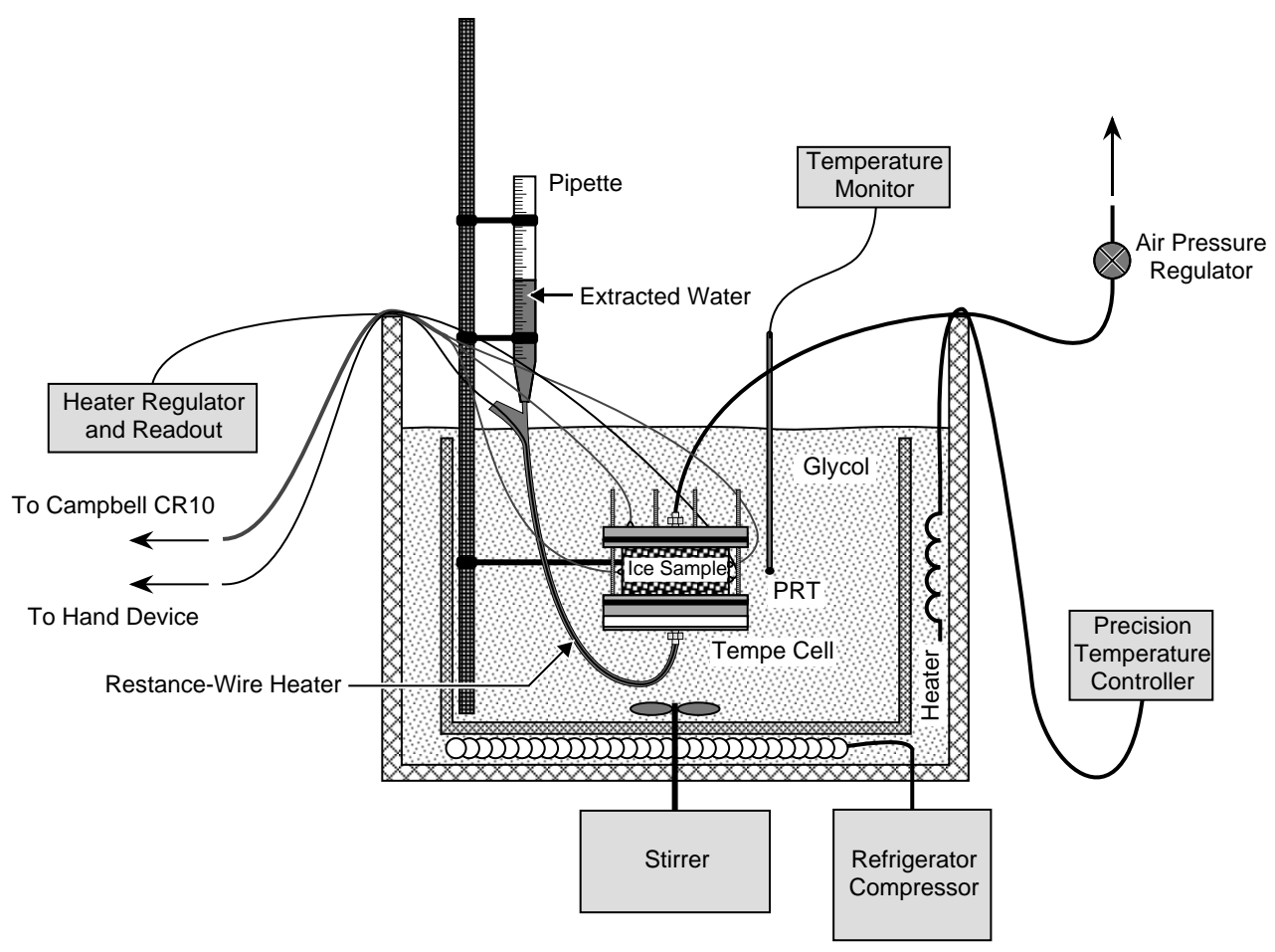

Figure 1. Experimental setup.

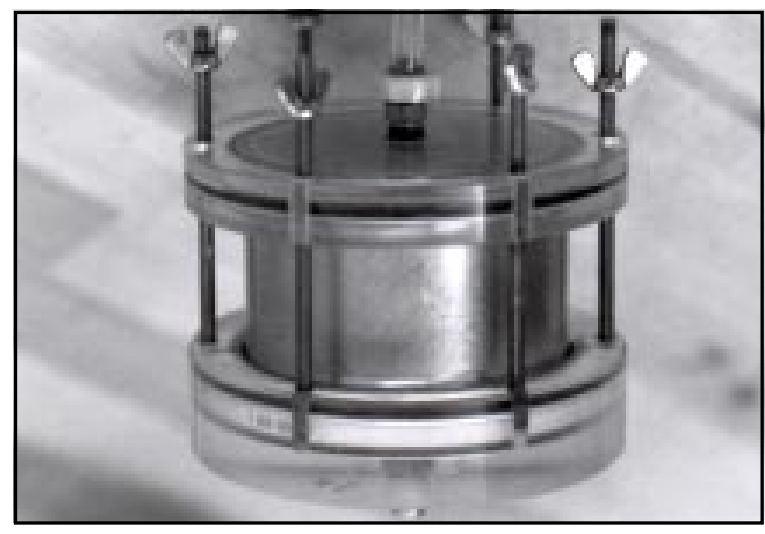

Figure 2. Ice sample is placed within a hermetically sealed Tempe cell.

initial run tested the viability of the experiment. For this run we used a quickly prepared ice sample (described in the next section) and monitored temperature of the ice bath with a single thermistor connected to a manual readout. High sensitivity of water levels to bath temperature indicated the need for continual and more accurate temperature monitoring. Thus, on the second experiment we added three thermistors and a highly accurate $\left( \pm 0.001^{\circ} \mathrm{C}\right)$ platinum resistance thermometer (PRT). Data from the thermistors were continuously collected on a Campbell CR10 and periodically transferred to a computer. The PRT was manually monitored with a S1220 Systemteknik temperature meter. The full combination as shown in Figure 1 was in place for the second experiment.

\section{SAMPLE PREPARATION, INSTALLATION, AND ANALYSIS}

We prepared two ice samples, both seeded with frazzle ice nucleated from singly distilled, supercooled water. To grow the first sample (Sample A), we placed a beaker of frazil slurry in a brine bath maintained at a temperature near $-20^{\circ} \mathrm{C}$ in a coldroom. Continuous agitation with a magnetic stirrer removed air bubbles ahead of the freezing front. This procedure produced a heterogeneous sample of coarse to fine-grained ice (Fig. $3 a, b)$. Large crystals on the order of centimeters grew in from the sides and bottom of the beaker and (at a slower rate) at the top of the slurry. The central, finegrained portion was agitated by the magnetic stirrer, which we removed for the final freezing. For the second sample we sought a refined technique that would produce a more homogenous and fine-grained sample. To prepare the second sample (Sample B), we placed a beaker of frazil ice on a $-25^{\circ} \mathrm{C}$ cold plate in a room where the temperature was kept slightly above $0^{\circ} \mathrm{C}$. Water froze from the bottom up while being stirred at 3 rpm with a motorized paddle held just above the freezing front on an adjustable mount. This procedure grew relatively fine-grained ice (Fig. 3c-d) at a rate of approximately $1 \mathrm{~cm}$ per hour. Both samples were disc-shaped, 


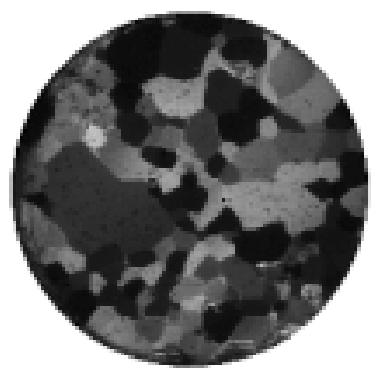

a. Bottom of Sample A.

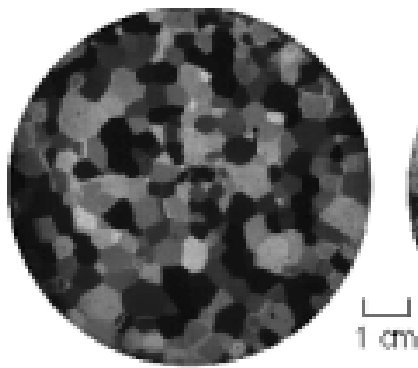

c. Bottom of Sample B.

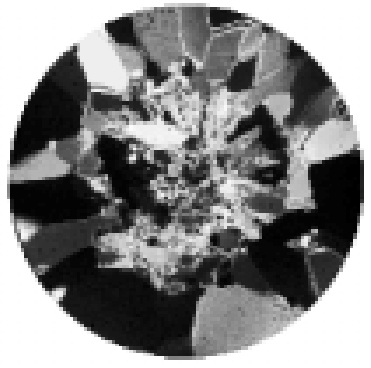

b. Top of Sample A.

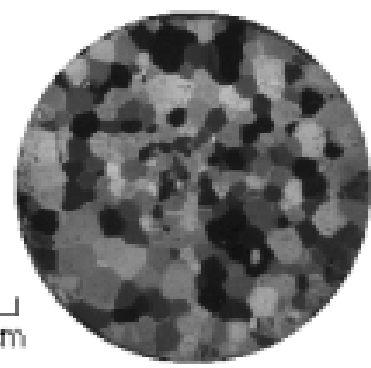

d. Top of Sample B.
Figure 3. Thin sections of ice samples under polarized light.

about $8.3 \mathrm{~cm}$ in diameter and 3.6 to $4.3 \mathrm{~cm}$ high. Samples A and B weighed 180 and 222 grams, respectively.

To assemble the Tempe cell, we filled the pipette, tubing, and the attached bottom plate with singly distilled water near the freezing point. We then moved the apparatus to a coldroom to add the ice sample and secure the remaining parts of the cell. To ensure good contact, we melted the bottom of the ice sample slightly before placement on the porous stone. During installation, water rose to fill a small gap between the ice sample and the 8.6-cm-diameter brass cylinder. After completion of the experiments, ice samples were returned to the coldroom and removed from the Tempe cell for analysis.

Figure 4 shows photographs of the rotted ice samples taken immediately after removal from the ice bath. Both samples show pronounced grain-boundary grooves with widths on the order of $1 \mathrm{~mm}$. Grooves initially appeared more pronounced than in the photographs, perhaps because refreezing had already started to occur before the photographs were taken. The bubbly central area in Sample A indicates that pressurized air entered the ice. Sample B was somewhat cloudy, but showed no distinct bubbly regions. Several candled grains along the sample sides flaked off with handling (Fig. 4c). Sample $B$ also evidenced possible surface melting towards the top of one side.

We prepared thin sections to analyze the ice struc- ture. Figures 3a-d display the grain cross sections under polarized light. Prior to sectioning, the ice was stored for several days at $-20^{\circ} \mathrm{C}$ and thus lost most evidence of rotting. By counting the number of grain-boundary intercepts per length of randomly oriented lines and taking the reciprocal, we determined grain sizes $(G)$ of $3.9 \mathrm{~mm}$ and $3.2 \mathrm{~mm}$ for Samples A and B, respectively.

We melted the remains of the ice samples and measured the impurities concentration with a Dionex ion chromatograph. This analysis yielded a chloride concentration of $35.8 \mathrm{ppm}$ for Sample A and $5.4 \mathrm{ppm}$ for Sample B, giving respective bulk molalities of $1.01 \times$ $10^{-3}$ moles kg-1 and $1.52 \times 10^{-4}$ moles kg-1 . Both concentrations were higher than expected for singly distilled water. The Hanover Water Company, for instance, reported $\mathrm{Cl}^{-}$concentrations of around $0.35 \mathrm{ppm}$ for tap water at the fire station near CRREL and Mader (1992b) measured concentrations two to three orders of magnitude less for her laboratory-grown samples. Mader,

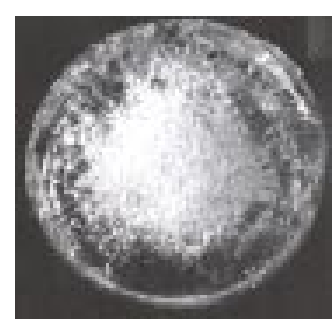

a. Top-down view of Sample A.

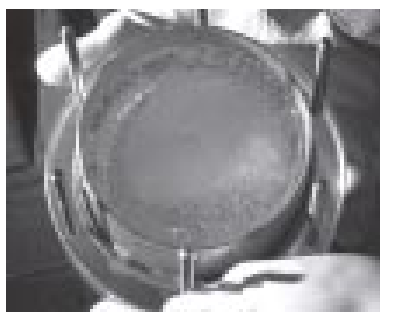

b. Top-down view of Sample $B$ within the Tempe cell.

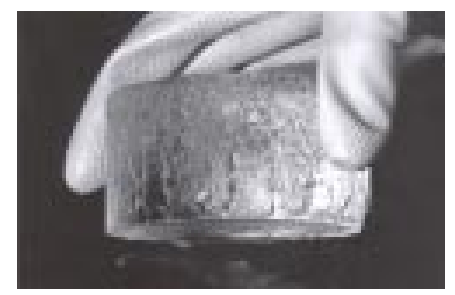

c. Side view of Sample B with its top downward. Note candled ice grains and possible surface melting at lower right.

Figure 4. Rotted ice samples from dismantled experiment. 


\begin{tabular}{|c|c|c|}
\hline Parameter & Functional relationship & Evaluated \\
\hline$G$ (grain size) & length/grain boundary intercepts & \\
\hline$\Phi$ (dihedral angle) & & $32^{\circ}$ \\
\hline$\theta$ (contact angle) & & $0^{\circ}$ \\
\hline$\sigma_{\mathrm{il}}, \sigma_{\mathrm{al}}$, and $\sigma_{\mathrm{iv}}($ surface tension $)$ & & $0.034,0.075,0.109\left(\mathrm{Jm}^{-2}\right)$ \\
\hline \multicolumn{3}{|l|}{ VEINS } \\
\hline$\alpha$ & $\alpha=\pi / 6-\Phi / 2$ & $14^{\circ}$ \\
\hline \multicolumn{3}{|l|}{$d_{\mathrm{v}}($ vein width) } \\
\hline$r_{\mathrm{v}}($ radius of curvature of vein) & $r_{\mathrm{v}}=d_{\mathrm{V}} / 2 \sin \alpha$ & $r_{\mathrm{v}}=d_{\mathrm{V}} / 0.4838(\mathrm{~m})$ \\
\hline$A_{\mathrm{V}}($ cross sectional area of vein) & $A_{\mathrm{v}}=r_{\mathrm{v}}^{2}\left(\sqrt{3} \sin ^{2} \alpha+\frac{3}{2} \sin 2 \alpha-3 \alpha\right)$ & $A_{\mathrm{v}}=0.0725 r_{\mathrm{v}}^{2}\left(\mathrm{~m}^{2}\right)$ \\
\hline$l$ (length of veins per unit volume) ${ }^{\mathrm{a}}$ & $l=3 / G^{2}$ & \\
\hline$R_{\mathrm{H}}$ (hydraulic radius) & 2 vein area/vein circumference & $R_{\mathrm{H}}=0.2044 d_{\mathrm{v}}(\mathrm{m})$ \\
\hline$k_{\mathrm{i}}$ (permeability) & $k_{\mathrm{i}}=\frac{\pi r_{\mathrm{H}}^{4}}{2 \sqrt{2} G^{2}\left(1+b^{4}\right)}$ & \\
\hline$r_{\mathrm{Av}}($ vein air-entry radius) & $r_{\mathrm{Av}}=\left(d_{\mathrm{v}} / 2\right)(\tan \pi / 6-\tan \alpha / 2)$ & $r_{\mathrm{Av}}=0.2273 d_{\mathrm{v}}(\mathrm{m})$ \\
\hline \multicolumn{3}{|l|}{ NODE } \\
\hline$R_{\mathrm{n}}$ (nodal volume/vein volume) ${ }^{\mathrm{b}}$ & $13.89 d_{\mathrm{v}} / G$ & \\
\hline$r_{\mathrm{An}}\left(\right.$ node air-entry radius) ${ }^{\mathrm{b}}$ & $r_{\mathrm{An}}=\left(d_{\mathrm{v}} / 2\right) \sqrt[3]{(3 \cdot 8.61) /(4 \pi)}$ & $r_{\mathrm{An}}=0.6357 d_{\mathrm{V}}(\mathrm{m})$ \\
\hline $\begin{array}{l}\text { LENS } \\
V_{\mathrm{L}}(\text { volume of lens) }\end{array}$ & $V_{\mathrm{L}}=\frac{2 \pi}{3}\left(2-3 \cos \frac{\phi}{2}+\cos ^{3} \frac{\phi}{2}\right) r_{\mathrm{L}}^{3}$ & $0.0093 r_{\mathrm{L}}^{3}\left(\mathrm{~m}^{3}\right)$ \\
\hline $\mathrm{S}_{\mathrm{V}}$ (surface to volume ratio of ice grain) ${ }^{\mathrm{d}}$ & $(6 \sqrt{3}+3) /(4 \sqrt{2} G)$ & $2.37 / G$ \\
\hline \multicolumn{3}{|l|}{ GROOVE (Fig. 8c) } \\
\hline$\beta$ & $\sin ^{-1}\left[\left(r_{\mathrm{g}} \cos (\Phi / 2) /\left(r_{\mathrm{a}}+r_{\mathrm{g}}\right)\right]\right.$ & \\
\hline
\end{tabular}

however, discarded the dirtier portions of her samples before analysis. Contamination from the preparatory brine bath used to grow Sample A undoubtedly contributed to the high concentration of $\mathrm{Cl}^{-}$. For Sample A, we assume that the $\mathrm{Cl}^{-}$cations are located within the ice lattice (Wolff 1996) and that an equal number of $\mathrm{Na}^{+}$anions are apportioned 50\% each between grain boundaries and veins (Harrison and Raymond 1976). Both samples also accreted impurities during postexperimental handling and sectioning (e.g., Fig. 4c). The proportional impact of this contamination is greater for Sample B.

Because expelled impurities concentrate ahead of the freezing front, they occur within a central core in Sample A and towards the top of Sample B. Mader (1992b) found that $89 \%$ of the impurities resided in $14 \%$ of the ice volume. With these proportions, the bulk molality for the "clean" part of the sample is reduced to a factor of 0.13 while that for the "dirty" part is enhanced to a factor of 6.4. Here we assume that impurities are immobile, although diffusion of solutes is pos- sible at these molality levels.* The vein bulk molality $m_{\mathrm{V}}$ for the clean part of Sample A is then $6.46 \times 10^{-5}$ moles $\mathrm{kg}^{-1}$. Because of possible post-experimental contamination, we take $m_{\mathrm{v}}$ as $1.00 \times 10^{-6}$ moles kg-1 for the clean part of Sample B, in line with Mader (1992b) and closer to the value computed from Hanover tap water.

\section{THEORY}

Ice structure is determined thermodynamically from combined thermal and mechanical stresses in the ice. Interfacial surface tensions define the geometry of air and water inclusions. Table 1 summarizes the geometri-

* In colder ice, the diffusivity of heat is much greater than the diffusivity of salt and limits the diffusion of impurities. As temperatures approach $0^{\circ} \mathrm{C}$ and with increasing molality, however, latent heat affects in ice lower its thermal diffusivity (Nye 1991a). Sample A has a sufficiently high molality that thermal and salt diffusivities are of the same magnitude for a temperature around $-0.01^{\circ} \mathrm{C}$ and thus some diffusion of solutes may occur. 
cal definitions and relationships used in this study. Liquid inclusions occur as veins along three-grain boundaries, as nodes where four veins join, and as lenses between two-grain boundaries. Veins dilate to widths of tenths of millimeters as ice nears $0^{\circ} \mathrm{C}$, and thus, together with nodes, form a permeable network for the flow of water. Nye (1989) provides a detailed description of the geometry of the vein-node system. Veins have a concave triangular cross section (Fig. 5a) which is fixed by the dihedral angle and does not vary with vein size. Nodes take the shape of tetrahedrons with nonspherical faces and open corners (Fig. 5b). Water lenses form spherical caps (Fig. 5c), where divergence at the icewater-ice juncture is again fixed by the dihedral angle. Because of the respective concave and convex shapes of the ice/water interfaces, water is under tension in veins and under pressure in lenses.

The phase-equilibrium temperature of water inclusions is defined by pressures in the ice and liquid phases and by impurities in the water. The change in equilibrium temperature $\Delta T$ from its bulk melt value $T_{0}$

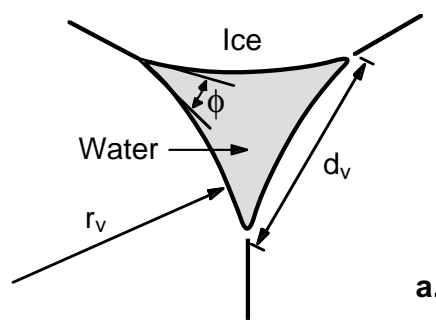

a. Vein cross section.
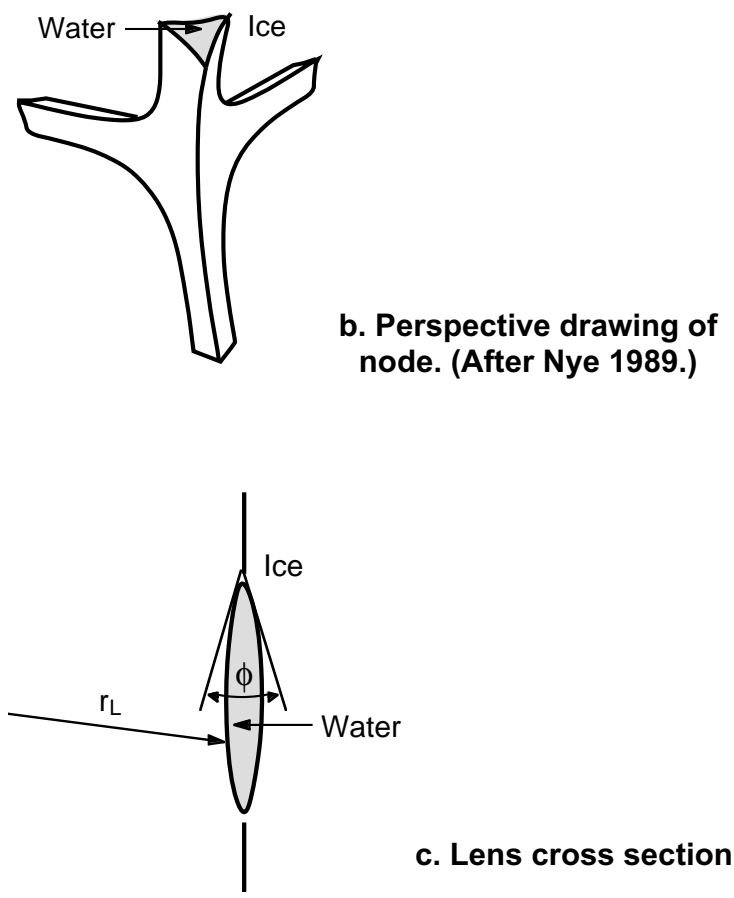

c. Lens cross section.

Figure 5. Geometry of water inclusions in ice. $\left(=273.15\right.$ kelvins or $\left.0^{\circ} \mathrm{C}\right)$ computes from the ClausiusClapeyron equation as

$$
\Delta T=\frac{T_{0}}{L_{\mathrm{i} \mid}}\left(\frac{p_{\mid}-p_{0}}{p_{\mid}}-\frac{p_{\mathrm{i}}-p_{\mathrm{o}}}{\rho_{\mathrm{i}}}\right)-K_{\mathrm{F}} C
$$

where $L_{\mathrm{i} \mid}$ is the latent heat of freezing $\left(3.335 \times 10^{5} \mathrm{~J}\right.$ $\left.\mathrm{kg}^{-1}\right), p_{0}$ is the reference pressure (atmospheric), $p_{\mid}$is the water pressure, $p_{\mathrm{i}}$ is the ice pressure, $\rho_{\mathrm{l}}$ is the density of water $\left(1000 \mathrm{~kg} \mathrm{~m}^{-3}\right), \rho_{\mathrm{i}}$ is the density of ice $\left(917 \mathrm{~kg} \mathrm{~m}^{-3}\right), C$ is the molality of the liquid water inclusion (moles $\mathrm{kg}^{-1}$ ), and $K_{\mathrm{F}}$ is the modal freezing point depression constant for water $\left(=1.855 \mathrm{~K} \mathrm{~kg} \mathrm{~mole}^{-1}\right)$. Thus, increases or decreases in the pressure of ice or water, respectively, lower the equilibrium temperature. The Laplace equation defines the pressure drop across the ice/water interface as $p_{\mathrm{i}}-p_{\mid}=2 \sigma_{\mathrm{i} \mid} / r_{\mathrm{il}}$, where $r_{\mathrm{il}}$ is the mean radius of curvature of the interface and $\sigma_{i l}$ its surface tension $\left(0.034 \mathrm{~J} \mathrm{~m}^{-2}\right)$. Taking the excess pressure in the ice as the gauge pressure, $p_{\mathrm{G}}$, and defining $p \vee$ by the Laplace equation, eq 1 becomes:

$$
\Delta T=\frac{T_{0}}{L_{\mathrm{i} \mid}}\left[p_{\mathrm{G}}\left(\frac{1}{\rho_{\mid}}-\frac{1}{\rho_{\mathrm{i}}}\right)-\frac{2 \sigma_{\mathrm{i} \mid}}{\rho_{\mid} r_{\mathrm{i} \mid}}\right]-K_{\mathrm{F}} C .
$$

The terms in eq 2 represent, respectively, temperature depression due to increased gauge or "atmospheric" pressure, interfacial curvature, and impurities. We assume that the gauge pressure acts equilaterally in the ice, but note that this is not necessarily the case.

The molality $C_{\mathrm{V}}$ of the vein-node system computes as $m_{\mathrm{v}} / v_{\mathrm{v}}$, where $m_{\mathrm{v}}$ is the vein bulk molality and $v_{\mathrm{v}}$ is the fractional volume of liquid. Applying thermodynamic reasoning, Nye (1989) computes the ratio of liquid volume in nodes to that in veins as $13.89 d_{\mathrm{v}} / G$. The fractional volume of liquid in the vein-node system is then $A_{\mathrm{v}} l\left(1+6.719 r_{\mathrm{v}} / G\right)$, where $A_{\mathrm{v}}$ is the cross-sectional area of a vein and $l$ the vein length per unit ice volume. Using the geometric relationships in Table 1, eq 2, and the Laplace equation, the equilibrium temperature for veins is (Lliboutry 1996, Mader 1992b*)

$$
\begin{aligned}
\Delta T_{\mathrm{v}} & =-7.413 \times 10^{-8} p_{\mathrm{G}}-\frac{2.785 \times 10^{-8}}{r_{\mathrm{v}}} \\
& -\frac{8.528 G^{3} m_{\mathrm{v}}}{r_{\mathrm{v}}^{2}\left(G+6.719 r_{\mathrm{v}}\right)}
\end{aligned}
$$

where $r_{\mathrm{V}}$ is the radius of curvature of the vein. Figure 6

\footnotetext{
* In deriving eq 3 , we do not include pumping of solutes by freezethaw contraction and expansion of the ice volume. This and smaller grain sizes for our samples yield smaller vein widths than observed by Mader (1992b).
} 


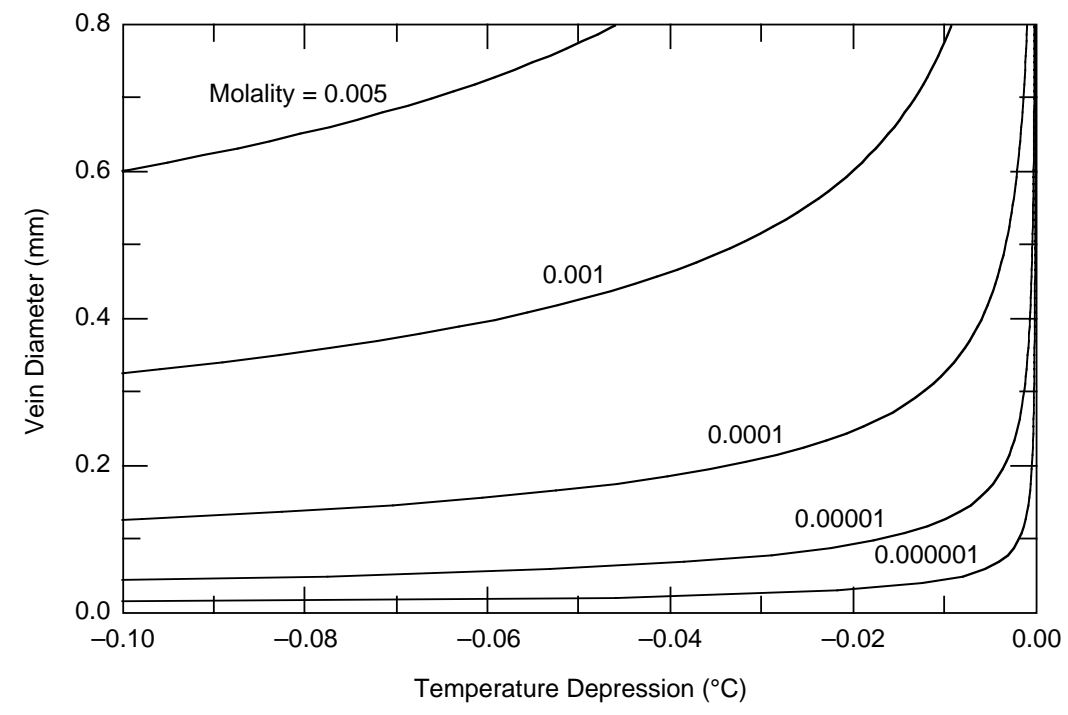

Figure 6. Vein diameter vs. equilibrium temperature for a range of vein bulk molalities $m_{\mathrm{v}}$. Computed from eq 3 , where $G=0.0032 \mathrm{~m}$ and $p_{\mathrm{G}}=0$.

shows vein diameter $d_{\mathrm{v}}\left(=0.4838 r_{\mathrm{v}}\right)$ as a function of temperature for a range of molalities that bracket our samples and Figure 7 shows the corresponding volume fraction of liquid water. The impurities term dominates the curvature term below about $-1 \times 10^{-5}{ }^{\circ} \mathrm{C}$. For these plots, the gauge pressure (or excess air pressure) is taken as 0 . At the maximum gauge pressure of about 1 bar or $15 \mathrm{PSI}$, the equilibrium temperature would be lowered overall by $0.007^{\circ} \mathrm{C}$ from that in Figure 7 . We note that the liquid volume fraction is quite low for the lower molalities and suggest that water released in the MC curves was primarily supplied by the contaminated portions of the samples.

The molality $C_{\mathrm{L}}$ of a lens is $\pi\left(r_{\mathrm{L}} \sin \phi / 2\right)^{2} m_{\mathrm{L}} /$ $\left(0.5 S_{\mathrm{V}} v_{\mathrm{L}}\right)$, where $S_{\mathrm{V}}$ is the surface-to-volume ratio of an ice grain, $r_{\mathrm{L}}$ is the radius of the lens interface, $m_{\mathrm{L}}$ is the lens bulk molality, and $v_{\mathrm{L}}$ is the lens volume. Again using the relationships in Table 1, the depression temperature for a lens is

$$
\begin{aligned}
\Delta T_{\mathrm{L}}= & -7.413 \times 10^{-8} p_{\mathrm{G}}-\frac{5.570 \times 10^{-8}}{r_{\mathrm{L}}} \\
& -\frac{40.19 G m_{\mathrm{L}}}{r_{\mathrm{L}}} .
\end{aligned}
$$

Although the temperature differences between veins and lenses are small, the resulting heat fluxes have important consequences for the ice structure. If the gauge

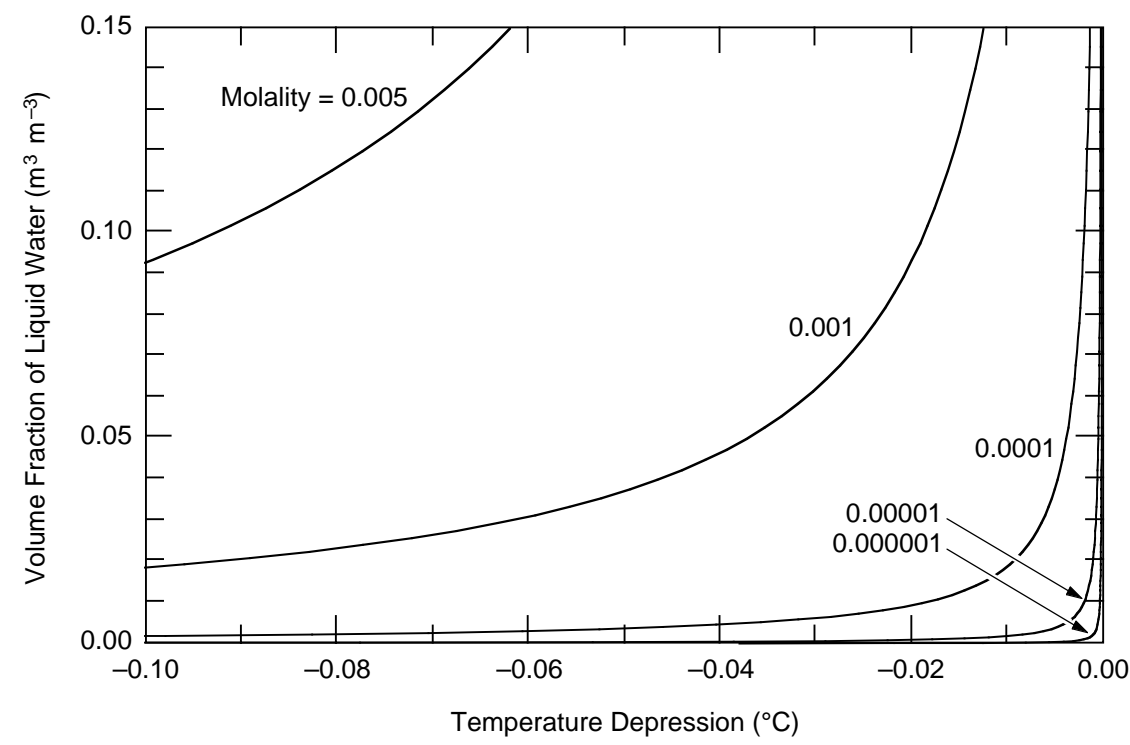

Figure 7. Volume fraction of liquid water vs. equilibrium temperature for a range of vein bulk molalities $m_{v}$. 
pressure acts equilaterally within the ice and the impurities concentrations are similar, then heat is directed towards the veins and the lenses will disappear. Impurities in the veins are potentially mobile, however, and thus $m_{\mathrm{L}}$ may exceed $m_{\mathrm{v}}$ in the contaminated region of the sample. Heat is then directed toward the colder lenses and the veins will shrink. If $m_{\mathrm{L}}=2 m_{\mathrm{v}}$ and $r_{\mathrm{V}}=$ $100 \mu \mathrm{m}$, the equilibrium lens radius is $13 \mu \mathrm{m}$. Thus while lenses may form, it is unlikely that they will grow large enough to coalesce. We must also consider the possibility that the stress does not act equilaterally. Nye and Mae (1972) observed the formation of lenses and shrinkage of veins following the short application of a compressive stress of 1.3 bar. They theoretically compute a critical overburden pressure of 0.23 bars for this effect to occur.

In this paper we investigate unsaturated ice and, thus, must also take into the account the thermodynamic state of ice when the vapor phase is present. In many ways, the saturated and unsaturated regimes in ice are analogous to the funicular and pendular regimes in snow (Colbeck 1973, Morris 1993). Here we conceptualize ice as a porous medium, similar to snow or soil, where the pores are either vein segments or nodes. Each pore has a critical entry pressure that must be reached before air can replace water. For a cylindrical pore of radius $R$, the radius of curvature of the air/liquid interface is $R / \cos \theta$, where $\theta$ is the contact angle (Fig. 8a). Without defining in detail the geometry of the interfacial surface in a vein, we specify an equivalent hemisphere whose radius $r_{\mathrm{Av}}$ is that of an inscribed circle (Fig. 8b). Although veins have a flared, trumpet-like shape at the surface (Nye 1991b), here we consider only interior veins with parallel faces. If the contact angle is 0 , the pressure drop across the interface is $p_{\mathrm{a}}-p_{\mid}=2 \sigma_{\mathrm{al}} / r_{\mathrm{Av}}$, where $\sigma_{\mathrm{il}}$ is the surface tension $\left(0.075 \mathrm{~J} \mathrm{~m}^{-2}\right)$ and $r_{\mathrm{Av}}=$ $0.2273 d_{\mathrm{v}}$ (Table 1). This pressure drop defines the airentry pressure $P_{\mathrm{Av}}$ as

$$
P_{\mathrm{Av}}=0.6600 / d_{\mathrm{v}}
$$

where $P_{\mathrm{Av}}$ is in Pascals and $d_{\mathrm{v}}$ in meters. A column of air replaces water in the vein when the pressure drop exceeds $P_{\mathrm{Av}}$. We note that air columns of smaller radius not touching the ice faces are mechanically unstable. The newly formed cylindrical meniscus is of higher tension than the hemisphere and immediately retreats into the three grain-boundary vertices, as shown in Figure $8 \mathrm{~b}$. Water inclusions in the unsaturated regime thus consist of concave triangular columns in the grainboundary grooves. Water cannot refill the vein until the gauge pressure is lowered to the point $P_{\mathrm{Av}} / 2$ where the menisci again touch. Thus the water re-entry pressure is half the air-entry value:

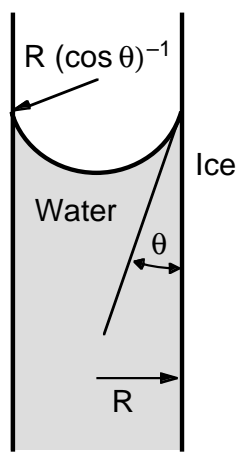

a. Air/liquid interface within a cylinder.

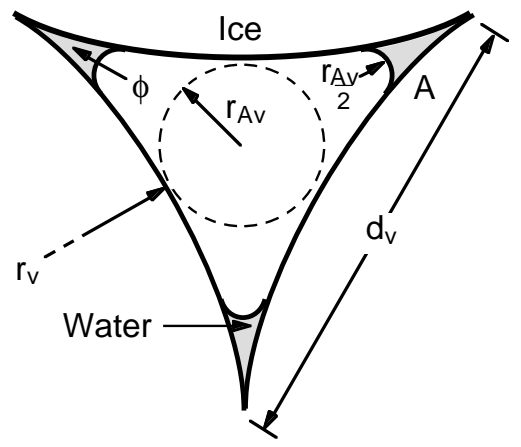

b. Air-entry radius of curvature within a vein and hypothesized location of liquid in an unsaturated vein.

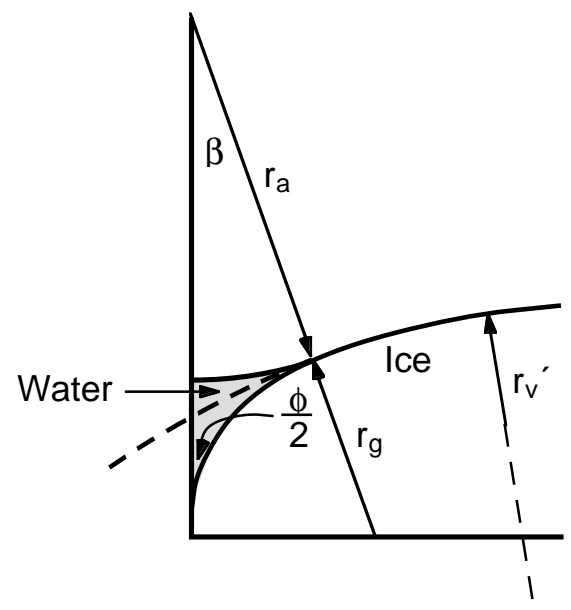

c. Grain-boundary groove.

Figure 8. Geometry of liquid inclusions in contact with air (not to scale).

$$
P_{\mathrm{Wv}}=0.3300 / d_{\mathrm{v}} \text {. }
$$

The configuration shown in Figure $8 \mathrm{~b}$ is not in mechanical equilibrium. We discuss potential changes in ice curvature in the following paragraph. Similarly, we use the radius of the inscribed sphere within a node to compute its air-entry pressure $P_{\mathrm{An}}$. Using the nodal geometry determined by Nye (1989), 


$$
P_{\text {An }}=0.2359 / d_{\mathrm{v}}
$$

roughly one third that of $P_{\mathrm{Av}}$. The water re-entry pressure is again half of this.

$$
P_{\mathrm{Wn}}=0.1180 / d_{\mathrm{v}} \text {. }
$$

In a series of interconnected pores, the smallest pore will block the entry of air and the largest pore will block the re-entry of water. In this idealized scheme of alternating veins and nodes, the air-entry pressure and water re-entry would be $P_{\mathrm{Av}}=0.6600 / d_{\mathrm{v}}$ and $P_{\mathrm{Wn}}=0.1180 /$ $d_{\mathrm{v}}$. For a vein diameter of $0.1 \mathrm{~mm}$ these evaluate as 6.6 $\mathrm{kPa}$ and $1.2 \mathrm{kPa}$. This scheme thus predicts a highly hysteretic moisture tension curve for ice.

When air replaces water within the vein system, mechanical and thermal equilibrium at the newly formed triple-phase junction is suddenly altered (point A in Fig. 8b). Application of the Laplace equations to the three interfaces defines the mechanical equilibrium (Colbeck 1979)

$$
\frac{2 \sigma_{\mathrm{al}}}{r_{\mathrm{al}}}=\frac{2 \sigma_{\mathrm{il}}}{r_{\mathrm{i}}}-\frac{2 \sigma_{\mathrm{ia}}}{r_{\mathrm{ia}}}
$$

where $\sigma_{\text {ia }}$ is the ice-air surface tension $\left(0.109 \mathrm{~J} \mathrm{~m}^{-2}\right)$, and $r_{\mathrm{al}}, r_{\mathrm{il}}$, and $r_{\mathrm{ia}}$ are the respective mean radii of curvature of the three interfaces. Figure $8 \mathrm{c}$ shows an open groove configuration, where pressurized air bounds the upper liquid surface. Here $r_{\mathrm{a}}=2 r_{\mathrm{a}}, r_{\mathrm{i}}=$ $2 r_{\mathrm{g}}$ and $r_{\mathrm{ia}}=2 r_{v}^{\prime}$, where $r_{v}^{\prime}$ is the radius of curvature of the exposed ice surface. The higher surface tension of the air/liquid interface dictates the groove's flared shape. Within a vein, these grooves must configure within an equilateral triangle, as shown in Figure 8b. In order to meet this additional restraint, we derive a somewhat surprising solution (not included in the report) in which the curvature of the vein walls changes from positive to negative.* If pressures in the liquid and ice are expressed relative to gauge pressure, eq 1 defines a new equilibrium temperature for the ice/water interface:

$$
\Delta T=\frac{T_{0}}{L_{\mathrm{i} \mid}}\left[p_{\mathrm{G}}\left(\frac{1}{\rho_{\mathrm{l}}}-\frac{1}{\rho_{\mathrm{l}}}\right)-\frac{\sigma_{\mathrm{a}}}{\rho_{\mathrm{|}} r_{\mathrm{a}}}-\frac{\sigma_{\mathrm{ia}}}{\rho_{\mathrm{i}} r_{\mathrm{v}}}\right]-K_{\mathrm{F}} C_{\mathrm{g}}
$$

which evaluates as

$$
\begin{aligned}
\Delta T_{\mathrm{g}}= & -7.413 \times 10^{-8} p_{\mathrm{G}}-\frac{6.143 \times 10^{-8}}{r_{\mathrm{a}}} \\
& -\frac{9.736 \times 10^{-8}}{r_{\mathrm{v}}}-1.855 C_{\mathrm{g}}
\end{aligned}
$$

* The solution is available from the authors upon request. where $C_{\mathrm{g}}$ is the concentration of impurities in the groove water. For a similar impurities concentration, the tighter curvature and increased surface tension of the air/liquid interface imply a lower equilibrium temperature relative to the saturated state (i.e., eq 3). Heat flow directed towards this colder region fosters melt. Mechanical equilibrium and increased pressure also suggest surface melting of the newly exposed vein wall. Without proposing a detailed equilibrium geometry for the unsaturated vein, we raise the possibility that veins exposed to air will change curvature and enlarge. This process is limited by dilution of the impurities by meltwater.

To describe water flow in ice, we also need to estimate the permeability of the vein system. We use the hydraulic radius $r_{\mathrm{H}}$ (2 vein area/vein circumference) to describe an equivalent radius for a cylindrical conduit. In terms of vein geometry (Fig. 5a), $r_{\mathrm{H}}=0.2044 d_{\mathrm{v}}$. Lliboutry (1996) computes permeability from Pouseilles' equation, multiplied by the vein density and divided by a tortuosity factor. Since water flow is constricted by the smallest pores in the network, we also add a vein diameter distribution factor (Dullien 1992). If the vein system consists of vein-node doublets with sizes $d_{\mathrm{v}}$ and $d_{\mathrm{v}} / b$, the harmonic mean permeability is $2 /$ $\left(1+b^{4}\right)$ times that with the larger size alone. Taking vein density as $2 / G^{2}$ and tortuosity as $\sqrt{2}$, the ice permeability $k_{\mathrm{i}}$ is then

$$
k_{\mathrm{i}}=\frac{\pi r_{\mathrm{H}}^{4}}{2 \sqrt{2} G^{2}\left(1+b^{4}\right)}=\frac{1.94 \times 10^{-3} d_{\mathrm{v}}^{4}}{G^{2}\left(1+b^{4}\right)} .
$$

Thus for $d_{\mathrm{V}}=5 \times 10^{-5} \mathrm{~m}, G=3.5 \times 10^{-3} \mathrm{~m}$, and $b=2$, $k_{\mathrm{i}}$ is $5.82 \times 10^{-17} \mathrm{~m}^{2}$. The permeability of ice is below that for soils of comparable pore size because of the low vein density.

$k_{\mathrm{i}}$ computed with eq 9 is the intrinsic or water-saturated value. Air blockages in unsaturated ice can greatly reduce this value.

\section{EXPERIMENTAL RUNS}

We made several runs for each of the samples, using the experimental setup described above. Several of these were marred by temperature fluctuations and are not reported here. For each run, we incrementally cycled the gauge pressure from 0 through 1 bar and back. Each pressure level was held for about two days or until the water level stabilized. We report only the equilibrium water level. Because of the long equilibrium times for ice, each run required many weeks to complete. Prior to a run, we rotted the ice sample for several days at a fixed bath temperature to obtain a given vein dilation, as shown in Figure 6. We noted the amount of water 


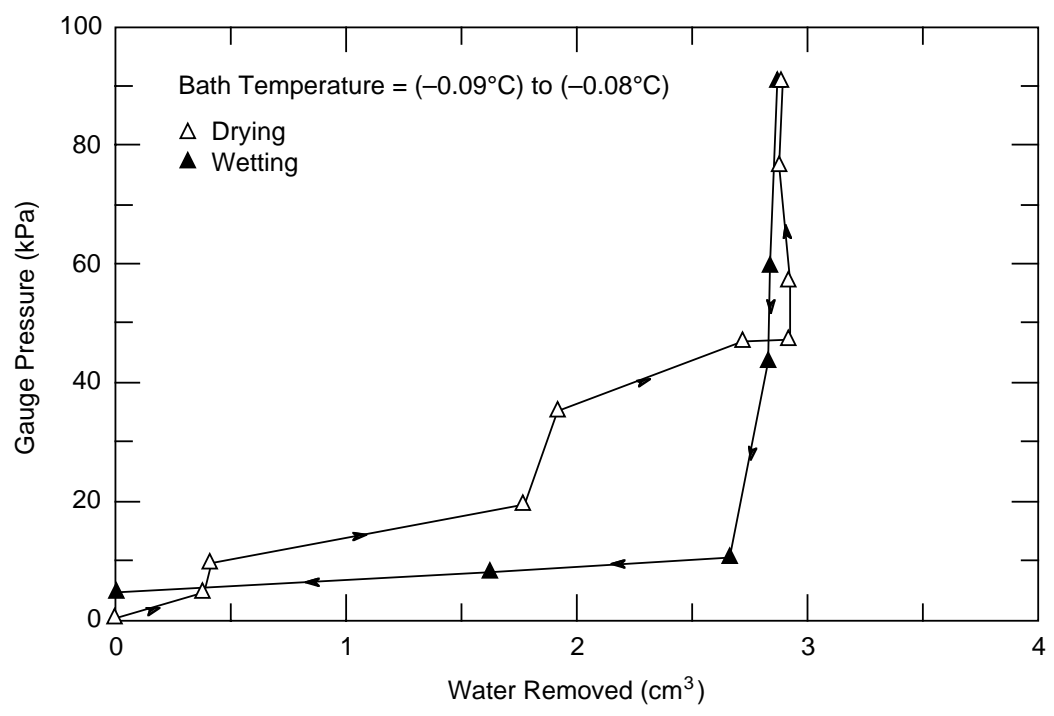

Figure 9. Volume of water exiting (open triangles) and re-entering (solid triangles) Sample $A$ vs. gauge pressure $\left(p_{G}\right)$ for bath temperatures between $-0.09^{\circ} \mathrm{C}$ and $-0.08^{\circ} \mathrm{C}$. The bath temperature drifted upwards 0.01 to $0.02^{\circ} \mathrm{C}$ at pressure levels of 20 and $47 \mathrm{kPa}$ on the drying curve.

forced from the ice by changes of water level in the pipette. Temperature, pressure level, and water level were monitored one to three times a day and temperature continuously for Sample B.

Figure 9 shows results from the initial run on Sample A with the bath temperature between -0.09 and $-0.08^{\circ} \mathrm{C}$. The plot shows that ice desaturates and rewets in response to changes in incremental pressure in a fashion similar to unsaturated soil. Temperature fluctuations of $\pm 0.01^{\circ} \mathrm{C}$ and changes in gauge pressure caused structural changes in the ice over the run. In addition, the sample was not homogenous. Localized impurities, grain size variations, and temperature gradients in the bath caused a potentially wide range of vein sizes. Measured temperature gradients in the bath suggest that the top of the sample was 0.01 to $0.02^{\circ} \mathrm{C}$ warmer than the bottom. Because of rapid conduction through the brass cylinder, sides of the sample were the most sensitive to temperature fluctuations. We hypothesize that smaller vein sizes towards the bottom of the sample control the entrance pressure while larger veins and nodes in warmer and contaminated regions control the liquid volume.

Figure 9 shows that air first entered Sample A at a pressure of $5 \mathrm{kPa}$ and water continued to be pulled from the ice up to a pressure of $57 \mathrm{kPa}$. Again, we theoretically relate the vein air-entrance pressure to its width as $P_{\mathrm{Av}}=0.6600 / d_{v}$, which suggests a range of vein sizes of 132 to $12 \mu \mathrm{m}$. Consistent with this, the ClausiusClapeyron equation (eq 3) predicts a vein width of 127 $\mu \mathrm{m}$ for the clean part of Sample A. Our tenfold range in vein widths is much larger than the twofold variation observed by Mader (1992a), but possibly reflects sample heterogeneity and temperature gradients in the bath. A total of $2.9 \mathrm{~cm}^{3}$ of liquid was removed from the sample. The volume fraction $v_{\mathrm{v}}$ for clean ice $(6.46 \times$ $10^{-5}$ moles $\mathrm{kg}^{-1}$ ) is around 0.001 and thus cannot account for this liquid. A volume fraction of 0.07 for the contaminated portion $\left(3.23 \times 10^{-3}\right.$ moles $\left.\mathrm{kg}^{-1}\right)$ yields $2.2 \mathrm{~cm}^{3}$ of water.* Larger increments in water at gauge pressures of 22 and $49 \mathrm{kPa}$ correspond to periods of upward temperature drift of 0.01 to $0.02^{\circ} \mathrm{C}$. After these occurrences, we reset the bath temperature to $-0.09^{\circ} \mathrm{C}$. In the reverse direction, Figure 9 shows water first re-entering the sample at $13 \mathrm{kPa}$. Recall that our theoretical estimate of water re-entry pressure is $P_{\mathrm{Wn}}=0.1180 / d_{\mathrm{v}}$, which predicts that water will re-enter the $12-\mu \mathrm{m}$ veins at a pressure of $10 \mathrm{kPa}$. Figure 9 thus supports our hypothesis that the MC curve of ice is highly hysteretic. Re-entry of the remaining $1.6 \mathrm{~cm}^{3}$ of water at a pressure of $5 \mathrm{kPa}$ occurred slowly over a two-week period, suggesting a low permeability for the ice and possibly a hysteresis effect. With gauge pressure reduced to 0 , an additional $0.5 \mathrm{~cm}^{3}$ of water entered the sample under the $2 \mathrm{kPa}$ gravitational head over the next two days.

During the next two weeks we again increased the gauge pressure up to $1 \mathrm{bar}$. Surprisingly, the water flow direction was unaffected by this reverse in pressure and continued to drop slowly at around $0.05 \mathrm{~cm}^{3}$ per day. We examine this anomalous behavior and issues concerning ice permeability in the next section.

The results of this first experiment were promising.

* Computed as $0.07 \times 222 \mathrm{~cm}^{3}$ (total volume) $\times 0.14$ (fraction of dirty ice). 


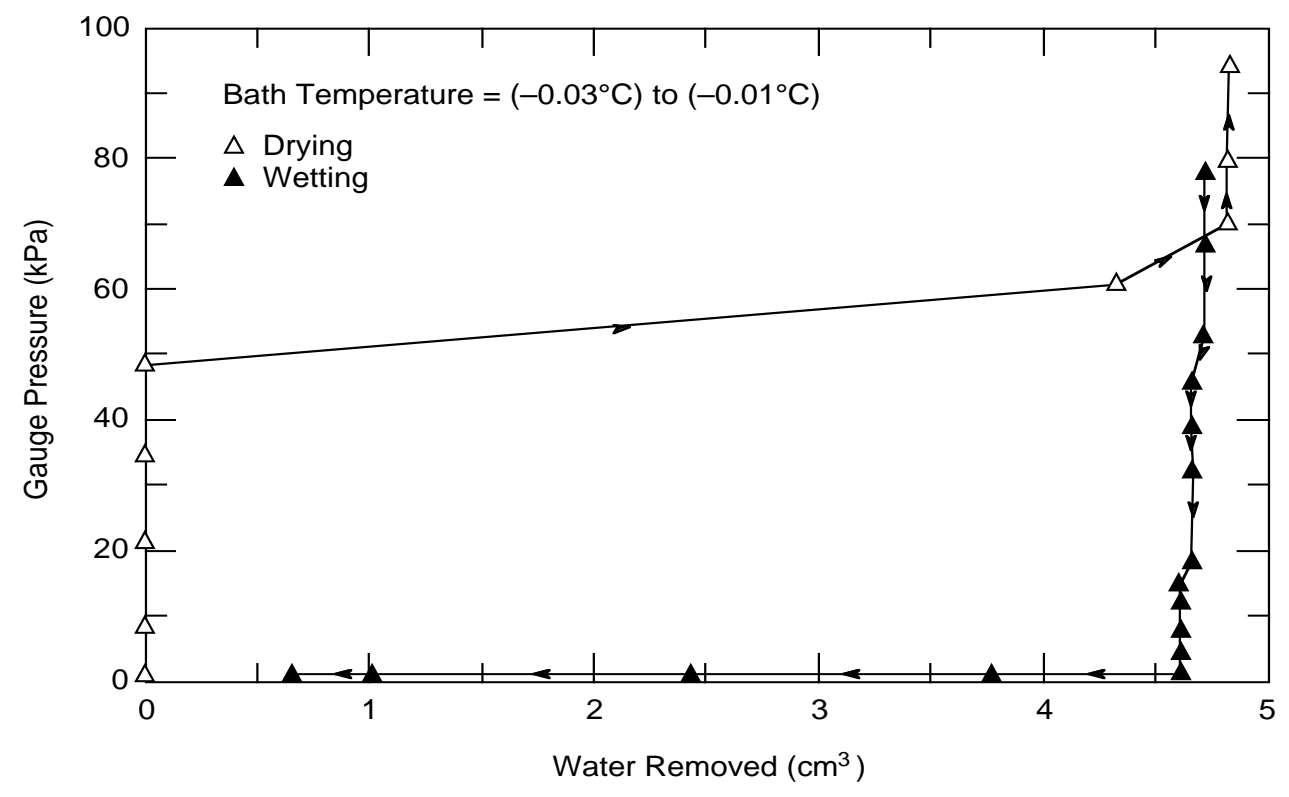

Figure 10. Volume of water exiting (open triangles) and re-entering (solid triangles) Sample B vs. gauge pressure $\left(p_{\mathrm{g}}\right)$ for bath temperatures between $-0.03^{\circ} \mathrm{C}$ and $-0.01^{\circ} \mathrm{C}$. The bath temperature warmed to $0.005^{\circ} \mathrm{C}$ for approximately two hours at a pressure level of $61 \mathrm{kPa}$.

We thus endeavored to refine the experiment by creating a purer and more homogenous sample and by monitoring the bath temperature more closely. For the second experiment, we rotted Sample B for one month at $-0.05^{\circ} \mathrm{C}$ to $-0.06^{\circ} \mathrm{C}$ and then began the first of four pressure cycles. None of these were particularly successful. In the first run, we incremented gauge pressure to $83 \mathrm{kPa}$ and back with only minor changes in water level. On the drying curve the water level increased by $0.05 \mathrm{~cm}^{3}$ at a pressure of $34 \mathrm{kPa}$ and on return curve it decreased by about half this amount when the pressure was reduced. The corresponding vein width of $20 \mu \mathrm{m}$ is consistent with a molality of $1 \times 10^{-6}$ moles $\mathrm{kg}^{-1}$. The tolerances in water level are so small, however, that we cannot attribute much significance to this value.

For the second run we increased the bath temperature to $-0.03^{\circ} \mathrm{C}$ to obtain greater vein dilation. Figure 10 shows the results of this run. For the first pressure increments the water level decreased slightly, reminiscent of this anomalous occurrence for the second run on Sample A. The 4.3-cc rise in water level at a pressure of $60 \mathrm{kPa}$ occurred when the bath temperature approached $0^{\circ} \mathrm{C}$ and slightly exceeded it for about an hour. At the time of observation and during most of the elevated period, the temperature was around $-0.01^{\circ} \mathrm{C}$. Because the equilibrium temperature for $4.3 \mathrm{~cm}^{3}$ of vein water is around $-0.001^{\circ} \mathrm{C}$ for the dirtier part of sample, surface melt undoubtedly contributed to this volume. After returning the bath temperature to $-0.03^{\circ} \mathrm{C}$, we incremented the pressure to $94 \mathrm{kPa}$ with no further loss of water. On the return phase, the water level decreased overall by $0.2 \mathrm{~cm}^{3}$ as the gauge pressure was decreased to $4 \mathrm{kPa}$. The first drop at $80 \mathrm{kPa}$ corresponds to a very small grain diameter of $2 \mu \mathrm{m}$. If the spread in vein diameters is again tenfold, this implies a maximum size of around $20 \mu \mathrm{m}$, consistent with run 1 . With the gauge pressure at 0 , water slowly re-entered the sample over the next month.

During the last week of the previous run, the bath temperature had warmed to near $-0.01^{\circ} \mathrm{C}$. Thus when we increased gauge pressure to $10 \mathrm{kPa}$ to begin run three, we immediately removed over $9 \mathrm{~cm}^{3}$ of meltwater in just a few hours. We reduced the pressure to 0 and all but $2.8 \mathrm{~cm}^{3}$ again re-entered the sample over the next month.

For the final run, the bath temperature was mostly between $-0.02^{\circ} \mathrm{C}$ and $-0.01^{\circ} \mathrm{C}$. About $2 \mathrm{~cm}^{3}$ of water was removed at a gauge pressure of $17 \mathrm{kPa}$. An additional $7 \mathrm{~cm}^{3}$ were removed as we incremented the gauge pressure to $93 \mathrm{kPa}$. Because of the sizable amounts of water, surface melting most likely contributed to the water volume. This close to the $0^{\circ} \mathrm{C}$, pressure melting becomes significant and could account for additional meltwater with increasing gauge pressure. No water reentered the sample on the depressurizing cycle or during the following week at 0 gauge pressure.

\section{PERMEABILITY}

Data points in Figure 11 show a time series of water re-entry volumes for the final months of runs 2 and 3 


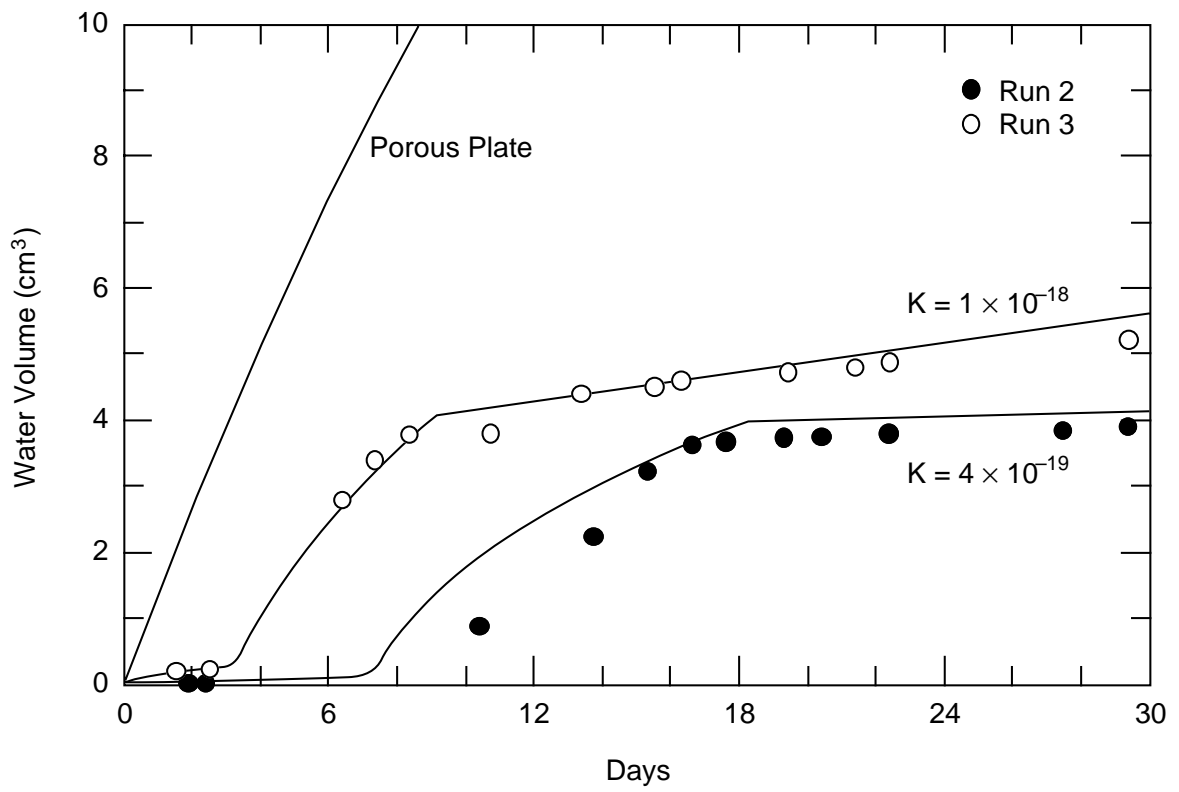

Figure 11. Days vs. volume of water re-entering Sample B. Solid circles are for run 2 and open circles for run 3 . Lines show computed flow rates for the porous plate alone and for hypothetical configurations of the ice sample.

on Sample B. Gauge pressure had been reduced to zero, but the height of water in the pipette created a pressure head at the bottom of the sample. In both data plots, water re-entry is at first quite slow, rises quickly for the next week or so, and then returns to a slower rate. Although it is possible that melt-induced structural changes caused this flow variation, bath temperatures were fairly steady over both time periods. Because the data plots are smooth and consistent, we attempt to model the water flow and thereby gain insight into the ice permeability. Figure 11 shows computed flow rates for the porous plate alone and for hypothetical configurations of the ice sample.

Figure 12 shows the simplified structure we assume for the analysis: a cylindrical stackup of the porous plate and a slightly narrower ice core, subject to a pressure head at the bottom of the porous plate. The initial gravitational head is a height $h_{0}$ of water in the pipette. The receding water level $z^{\prime}$ in the pipette relates to the rising level $z$ in the sample as $z^{\prime}=\phi A_{\mathrm{r}} z$, where $A_{\mathrm{r}}$ is the ratio of the sample area to the pipette area and $\phi$ is the ice porosity ahead of the water front. We assume a onedimensional treatment, but note that this is valid only in the absence of a radial pressure gradient beneath the plate. A uniform pressure head is possible if the resistance-wire heater (Fig. 1) kept the area beneath the plate from totally freezing. If this area were instead blocked by ice, we estimate that the radial gradient would slow the upward velocity of the water front by roughly oneseventh (e.g., Muskat 1937).

We model the water flow with Darcy's law:

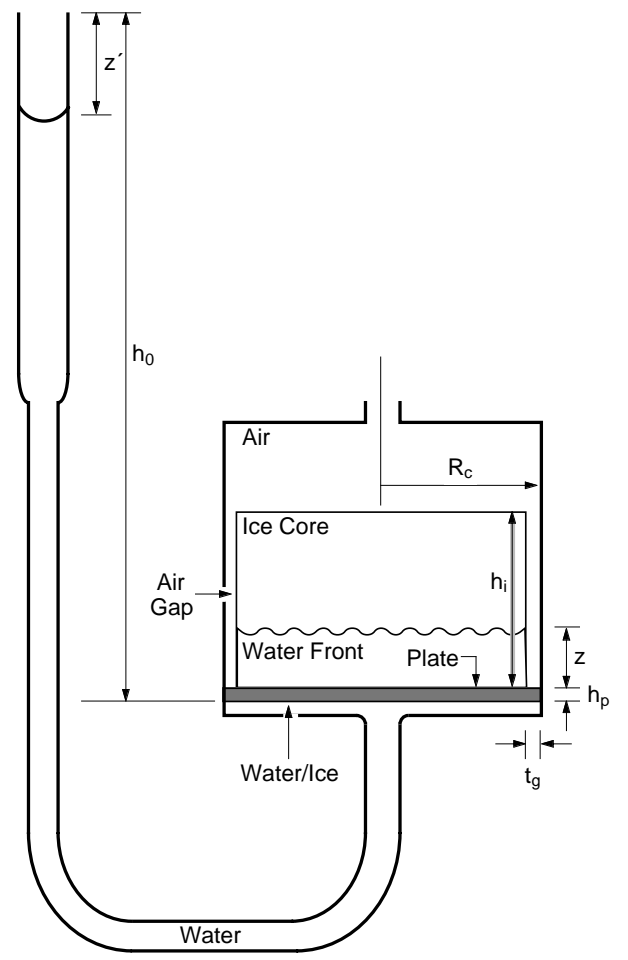

Figure 12. Idealized ice configuration used in flow computations. Not to scale. 


$$
\frac{\phi \Delta z}{d t}=-\frac{1}{\mu}\left[\frac{\left(z+z_{\mathrm{p}}\right) k_{\mathrm{i}} k_{\mathrm{p}}}{k_{\mathrm{p}} z+k_{\mathrm{i}} z_{\mathrm{p}}}\right]\left(\nabla p+\rho_{\mid \mathrm{g}}\right)
$$

where $\mu$ is the viscosity of water $\left(1.789 \times 10^{-3}\right)$, g the gravitational constant $\left(9.8 \mathrm{~m} \mathrm{~s}^{-2}\right), \rho$ | the density of water $\left(1000 \mathrm{~kg} \mathrm{~m}^{-3}\right)$, and $\nabla p$ the pressure gradient. The quantity in the brackets is the mean harmonic permeability, where $k_{\mathrm{i}}$ is the ice permeability, $z_{\mathrm{p}}$ the thickness of the porous plate, and $k_{\mathrm{p}}$ the plate permeability. Pressures at the top of the rise $z$ and at the bottom of the porous plate are respectively the nodal entry tension, $-P_{\mathrm{Wn}}$, and the gravitational pressure, $\rho \operatorname{g}\left(h_{0}-z^{\prime}\right)$. These act over the combined distance $h_{\mathrm{p}}+z$. Integrating eq 10 we obtain an implicit equation of rise height in terms of time

$$
\frac{z}{A k_{\mathrm{i}}}-\frac{B}{A^{2}} \log \left(\frac{P_{0}-\rho_{\mid} g z c}{P_{0}}\right)=t
$$

where

$$
\begin{aligned}
& A=\frac{-c \rho_{\mid} g}{\mu \phi} \\
& B=\frac{P_{0}+\rho_{\mid} g c k_{\mathrm{i}} t_{\mathrm{p}} / k_{\mathrm{p}}}{\mu \phi k_{\mathrm{i}}}
\end{aligned}
$$

and where $P_{0}=P_{\mathrm{Wn}}+\rho \mid \mathrm{g} h_{0}$, and $c=\left(1+\phi A_{\mathrm{r}}\right)$. With varying parameters and boundary conditions (Table 2 ), eq 11 describes the three flow phases observed in Figure 11. We explain the three phases as follows: 1) water rises under tension within the central ice core until the veins are saturated, 2) water rises under a gravitational head to fill the air gap, and 3) water flows to a seepage face at the top of the ice sample.

The hypothesis of unsaturated flow in phase 1 is the most speculative of the three scenarios. Flow under tension prevents entry of water into the side air gap and hypothetically explains the observed delays of approximately three and seven days in Figure 11. We recall that slow equilibrium times also prevented complete resaturation on the wetting cycle for runs 1 of both samples. In these cases, water continued to enter the ice after the next drying cycle was initiated (e.g., drying curve in Fig. 10). Solution of eq 11, subject to the observed delay times and a rise height $z$ of $h_{\mathrm{i}}$, yields extremely low ice permeabilities of around $4 \times 10^{-19}$ and $1 \times 10^{-18}$, respectively, for runs 2 and 3 . Corresponding air entry values are 4.3 and $3.4 \mathrm{kPa}$. Appendix A provides details on the solution.

Once the sample is saturated, water rises rapidly to fill the air gap. Tension at the top of the rise $\left(-P_{\mathrm{Wn}}\right)$ is now 0 and the porosity is 1 . We determine the thickness of the air gap $t_{\mathrm{g}}$ from the observed volumes of water re-entry during phase 2 . Note that the area ratio $A_{\mathrm{r}}$ is now close to 1 , since we limit flow to the air gap. Solution of eq 11 for a rise height of $h_{\mathrm{i}}$ and for the observed times to complete phase 2 yields permeabilities of $1 \times 10^{-15}$ and $3 \times 10^{-15} \mathrm{~m}^{2}$. Thus, the predicted permeability of the newly frozen ice in the air gap is much larger than that for the central core.

In order to not "over-fit" the data, we use the same permeabilities for phase 3 that were determined for the central core in phase 1 . These $k_{\mathrm{i}}$ values slightly overpredict the flow rates for runs 2 and 3 . With $b=4$, a middle $k_{\mathrm{i}}$ value of $7 \times 10^{-19} \mathrm{~m}^{2}$ corresponds to vein doublet widths of 31 and $8 \mu \mathrm{m}$. These widths are in line with values suggested by the MC runs.

The higher permeabilities for phase 2 are consistent with greater vein dilation in ice at the sides of the sample, but also suggest that by comparison ice in the central core underwent structural changes during the experiments. All four runs with sufficient data for analy-

\begin{tabular}{|c|c|c|c|c|c|}
\hline & Pha & se 1 & \multicolumn{2}{|c|}{ Phase 2} & Phase 3 \\
\hline$h_{\mathrm{p}}(\mathrm{m})$ & \multicolumn{2}{|c|}{0.00635} & & & \\
\hline$h_{\mathrm{i}}(\mathrm{m})$ & \multicolumn{2}{|c|}{0.043} & & & \\
\hline$R_{\mathrm{C}}(\mathrm{m})$ & \multicolumn{2}{|c|}{0.043} & & & \\
\hline$k_{p}\left(m^{2}\right)$ & \multicolumn{2}{|c|}{$6.35 \times 10^{-16}$} & & & \\
\hline$h_{0}(\mathrm{~m})$ & \multicolumn{2}{|c|}{0.250 .29} & 0.25 & 0.29 & $0.21 \quad 0.25$ \\
\hline$A_{\mathrm{r}}$ & \multicolumn{2}{|c|}{58.1} & 0.837 & 0.884 & 58.1 \\
\hline$t_{\mathrm{g}}(\mathrm{m})$ & \multicolumn{2}{|c|}{0.0003} & \multicolumn{2}{|c|}{0.0003} & 0 \\
\hline$k_{\mathrm{i}}$ & $4 \times 10^{-19}$ & $1 \times 10^{-18}$ & $1 \times 10^{-15}$ & $3 \times 10^{-15}$ & $4 \times 10^{-19} \quad 1 \times 10^{-18}$ \\
\hline$b$ & 4.0 & 4.0 & \multicolumn{2}{|c|}{ na } & na \\
\hline$\Phi$ & 0.001 & 0.001 & \multicolumn{2}{|c|}{1.0} & 1.0 \\
\hline$P_{\mathrm{wn}}(\mathrm{kPa})$ & \multicolumn{2}{|c|}{4.33 .4} & \multicolumn{2}{|c|}{0} & 0 \\
\hline
\end{tabular}
sis showed long equilibrium times, on the order of weeks, for the wetting curve. We speculate that veinwall melting during the desaturation process may have 
led to shrinkage of nearby veins, thus increasing the spread of vein width sizes. Blockage of water flow by entrapped air is another likely cause of reduced ice permeability. Both of the causes presume that air enters the veins. Redistribution of impurities would lead to vein shrinkage and growth, respectively, in contaminated and purer regions of the samples.

\section{CONCLUSIONS}

From the relative success of the MC experiment and from physical evidence of a large, bubbly region within the rotted ice, we conclude that air did permeate Sample A. Although water volumes were somewhat affected by temperature fluctuations, our data suggest that ice desaturates and rewets under pressure in a fashion similar to unsaturated soil. Air entry and water re-entry pressures generally supported our theoretical estimates (eq $5 \mathrm{a}$ and $5 \mathrm{~d}$ ) and predictions from the Clausius-Clapeyron equation (eq 6). The observed MC curve for this one experiment was highly hysteretic, in line with our idealized flow path model of alternating vein segments and nodes. Because of small water volumes and intervening melt episodes, MC results were much less conclusive for Sample B. The few usable data points, however, are again in line with theoretical estimates. Ancillary information on flow rates through Sample B corroborates the $\mathrm{MC}$ runs and supports the hypothesis that air entered the sample. For two runs, we speculate that water re-entry into the side air gap was delayed by three and seven days until the sample was resaturated. For another, water levels continued to drop when pressure was reversed upwards, thus suggesting the continued flow of water under tension into unfilled airways.

We propose that water inclusions reside in the vertices of air-filled veins and take the form of concave triangular columns. Thermal and mechanical equilibrium requires a lowered equilibrium temperature and perhaps a reversal in curvature of the vein wall through melting. The formation of these near-cylindrical conduits has important implications for the permeability of ice in non-laboratory settings. Finer-grained soils underlying basal ice could draw water from the veins and, in warm spring conditions, began this process of vein enlargement. Our laboratory results show that resaturated ice under hydrostatic tension is nearly impermeable, with permeabilities on the order of $1 \times 10^{-18}$ $\mathrm{m}^{2}$. Low permeabilities may result from air entrapment.

We conclude that moisture-tension experiments on ice are doable and offer an alternative tool for studying ice thermodynamics in the temperate regime. Temperature fluctuations were the major drawback in this experiment and could be stabilized by adding an encapsulating brine bath around the Tempe cell. We suggest increasing the diameter of the sample and Tempe cell to gain more water outflow and to use a pipette with finer gradations. Controlled doping of the sample, unwittingly accomplished for Sample A, would also increase the water volume. Growing a larger sample and discarding the contaminated ice would ensure greater homogeneity.

\section{LITERATURE CITED}

Black, P.B. (1986) RIGIDICE model of frost heave and its input functions. Ph.D. thesis, Cornell University, Ithaca, New York.

Black, P.B. (1990) Three functions that model empirically measured unfrozen water content data and predict relative hydraulic conductivity. U.S. Army Cold Regions Research and Engineering Laboratory, CRREL Report 90-5.

Black, P.B., and A.R. Tice (1989) Comparison of soil freezing and soil water curve data for Windsor sandy loam. Water Resources Research, 25(10): 2205-2210. Colbeck, S.C. (1973) Theory of metamorphism of wet snow. U.S. Army Cold Regions Research and Engineering Laboratory, Research Report 313.

Colbeck, S.C. (1976) Water flow through veins in ice. U.S. Army Cold Regions Research and Engineering Laboratory, CRREL Report 76-6.

Colbeck, S.C. (1979) Grain clusters in wet snow. Journal of Colloidal and Interface Science, 72: 371-384.

Dullien, F.A.L. (1992) Porous Media. Fluid Transport and Pore Structure. San Diego: Academic Press, second edition, p. 1-574.

Harrison, W.D., and C.F. Raymond (1976) Impurities and their distribution in temperate glacier ice. Journal of Glaciology, 15(74): 173-181.

Jordan, R. (1991) A one-dimensional temperature model for a snow cover: Technical documentation for SNTHERM.89. U.S. Army Cold Regions Research and Engineering Laboratory, Special Report 91-16.

Jordan, R.E., E.LAndreas, and A.P. Makshtas (1999) Heat budget of snow-covered sea ice flow at North Pole 4. Journal of Geophysical Research-Oceans, 104(C4): 7785-7806.

Lliboutry, L. (1996) Temperate ice permeability, stability of water veins and percolation of internal meltwater. Journal of Glaciology, 42(141): 201-211.

Mader, H.M. (1992a) Observations of the water-vein system in polycrystalline ice. Journal of Glaciology, 38(130): 333-347.

Mader, H.M. (1992b) The thermal behavior of the water-vein system in polycrystalline ice. Journal of Glaciology, 38(130): 359-374.

Morris, E.M. (1993) A theoretical determination of the characteristic equation of snow in the pendular regime. Journal of Glaciology, 36(1123): 179-187.

Muskat, M. (1937) The Flow of Homogeneous Fluids 
Through Porous Media. New York and London: McGrawHill Book Company, Inc.

Nye, J.F. (1989) Thermal behaviour of glacier and laboratory ice. Journal of Glaciology, 35(119): 17-22.

Nye, J.F. (1991a) The geometry of water veins and nodes in polycrystalline ice. Journal of Glaciology, 37(127): 401-413.

Nye, J.F. (1991b) The rotting of temperate ice. Journal of Crystal Growth, 113: 465-476.
Nye, J.F., and S. Mae (1972) The effect of non-hydrostatic stress on intergranular water veins and lenses in ice. Journal of Glaciology, 11(61): 81-101.

Wolff, E.W. (1996) Location, movement and reactions of impurities in solid ice. In Chemical Exchange Between the Atmosphere and Polar Snow (E.W. Wolff and R.C. Bales, Ed.). N NATO ASI Series, vol. 143. Heidelberg: Springer-Verlag. 


\section{APPENDIX A: SOLUTION OF EQUATION 12 FOR FLOW UNDER TENSION}

We model the water pathway with the idealized vein doublet discussed above, where the dimensions of the smaller vein-node pair are $1 / b$ th the larger. Repeating eq 9:

$$
k_{\mathrm{i}}=\frac{1.94 \times 10^{-3} d_{\mathrm{v}}^{4}}{\mathrm{G}^{2}\left(1+b^{4}\right)}
$$

where $G=3.2 \times 10 \mathrm{~m}^{-3}$. The volume $v$ of water re-entering the sample is $\Phi V$, where $V$ $(=250 \mathrm{cc})$ is the sample volume. With $v$ measured as $0.2 \mathrm{cc}$ we take porosity as about 0.001 . The water re-entry pressure $P_{\mathrm{wn}}$ is given by eq $5 \mathrm{~d}$

$$
P_{\mathrm{Wn}}=0.1180 / d_{\mathrm{v}} .
$$

For assumed values of $k_{\mathrm{i}}$ and $b$, eq A1 yields the vein width $d_{\mathrm{v}}$. Eq A2 then provides the re-entry pressure $P_{\mathrm{Wn}}$.

We solve eq 11, A1 and A2 simultaneously by trial and error, inputting values for $k_{\mathrm{i}}$ and $b$ until the observed time is matched for a height of $z=0.043$. This simplified scenario should provide order-of-magnitude estimates of $k_{\mathrm{i}}$. 


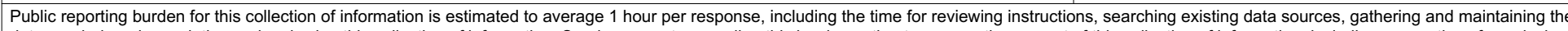

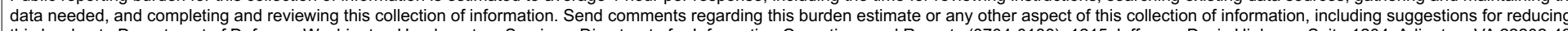

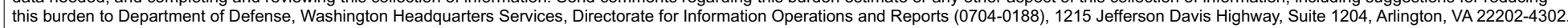

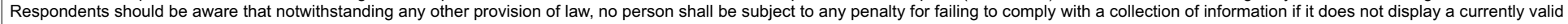
OMB control number. PLEASE DO NOT RETURN YOUR FORM TO THE ABOVE ADDRESS.

\begin{tabular}{|l|l|}
\hline $\begin{array}{l}\text { 1. REPORT DATE }(D D-M M-Y Y) \\
\text { September } 2001\end{array}$ & $\begin{array}{l}\text { 2. REPORT TYPE } \\
\text { Technical Report }\end{array}$ \\
\hline 4. TITIE AND SUBTITL &
\end{tabular}

4. TITLE AND SUBTITLE

2. REPORT TYPE
Technical Report
3. DATES COVERED (From - To)

5a. CONTRACT NUMBER

5b. GRANT NUMBER

5c. PROGRAM ELEMENT NUMBER

5d. PROJECT NUMBER

61102/AT24

5e. TASK NUMBER

5f. WORK UNIT NUMBER

AT24-SP-001

8. PERFORMING ORGANIZATION REPORT NUMBER

ERDC/CRREL TR-01-13

10. SPONSOR / MONITOR'S ACRONYM(S)

11. SPONSOR / MONITOR'S REPORT NUMBER(S)

Department of Defense

Washington, D.C. 20314

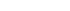

\section{DISTRIBUTION / AVAILABILITY STATEMENT}

Approved for public release; distribution is unlimited.

Available from NTIS, Springfield, Virginia 22161.

13. SUPPLEMENTARY NOTES

\section{ABSTRACT}

This study examines the moisture-tension constituent relationship of ice near $0^{\circ} \mathrm{C}$ by measuring its moisture characteristic curve. In this novel approach, we held ice samples in a Tempe cell submerged in a cold bath and removed water from the ice veins through incremental increases in air pressure. Observed air entry and water re-entry pressures generally support an idealized flow path model of alternating vein segments and nodes. Re-entry of water into the air-filled ice samples occurred slowly over a period of weeks, suggesting low permeabilities on the order of $1 \times 10^{-18} \mathrm{~m}^{2}$. We conclude that ice desaturates and rewets in a manner similar to soils, with entry pressures on the order of silts.

\section{SUBJECT TERMS \\ Capillary tension \\ Ice \\ Melting temperature \\ Permeability}

16. SECURITY CLASSIFICATION OF:

a. REPORT

$\mathrm{U}$

b. ABSTRACT

U

\begin{tabular}{|c|c|}
\hline \multicolumn{2}{|l|}{ F: } \\
\hline STRACT & c. THIS PAGE \\
\hline $\mathrm{U}$ & $\mathrm{U}$ \\
\hline
\end{tabular}

17. LIMITATION OF
OF ABSTRACT
U

18. NUMBER OF PAGES

19 